Revista Iberoamericana, Vol. LXXIX, Núm. 242, Enero-Marzo 2013, 57-74

\title{
RETRATO DE RESISTENCIAS EN UNA FOTOGRAFÍA DE AUGUSTO C. SANDINO
}

\author{
POR \\ Julia M. Medina \\ University of San Diego
}

\section{A PRIMERA VISTA}

En el contexto de Nicaragua, las imágenes fotográficas de Augusto C. Sandino son los textos fundacionales del imaginario iconográfico de resistencia. Dichas imágenes, que venían ya mediadas por los signos de la Revolución Mexicana y que, desde luego, ahora forman parte de los referentes de la Revolución Cubana, siguen circulando en la rearticulación del sandinismo y en los discursos nacionalistas de Nicaragua. El archivo de imágenes de Sandino es amplio, y constituye una narrativa significativa en la inscripción del sujeto masculino como protagonista histórico de la lucha anti-imperialista. En este artículo no es mi intención catalogar las tantas representaciones suyas, pero sí examinar un retrato tomado en Mérida (Yucatán, México), en 1929, con el objetivo de exponer la construcción de las capas narrativas visuales de cierta forma histórica de resistencia. ${ }^{1}$ A través de un análisis inmanente, la lectura de esta imagen nos permite entrever no sólo las corrientes de su contexto histórico, sino también anticipar los desfases ideológicos entre su proyecto y su legado. ${ }^{2}$

Consecuente con la crítica inmanente, la cuestión que se destaca a primera vista en esta imagen fotográfica es el efecto teatral que produce en su conjunto: la pose, la composición, el vestuario y lo que puede entenderse como los objetos del atrezzo; -elementos por sí mismos con connotaciones que revierten e intermedian contextos transnacionales como los de México y Cuba-. Esta hiper-teatralidad o performance de resistencia resulta en una disonancia visual entre el referente (Augusto C. Sandino) y el significante (el guerrillero/hombre de acción). En otras palabras, esta imagen fotográfica muestra una ambigüedad representativa que vacila entre la masculinidad guerrillera y

1 Quisiera agradecer al Instituto de Historia de Nicaragua y Centroamérica por el uso de esta fotografía.

2 La crítica inmanente se refiere a un procedimiento metodológico de la tradición del materialismo histórico, que propone que el objeto de estudio contiene, en su propia estructura y forma, las contradicciones de su coyuntura histórica. 


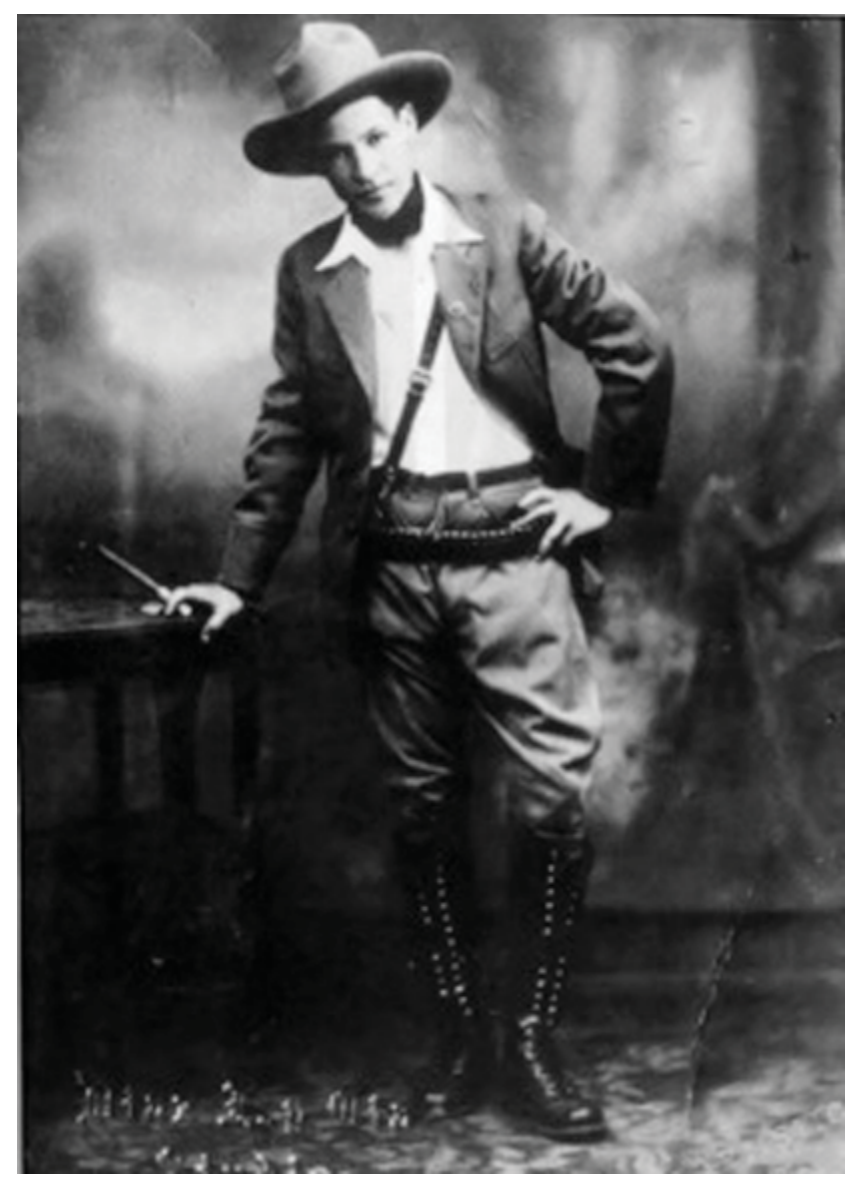

la de un dandi. ${ }^{3} \mathrm{Mi}$ argumento se centra en este desfase de la imagen de Sandino, una discordancia que no sólo mistifica su resistencia y codifica el mosaico ideológico que caracteriza su pensamiento según sus propios escritos, sino que también anticipa la manipulación histórica que se ha venido produciendo en torno a su figura. He elegido esta imagen fotográfica como punto de partida, no porque sea la más representativa de

3 Ricardo Piglia me señaló este elemento del dandi en la imagen de Sandino en una consulta (UC Davis, 2001). Sin embargo, vale clarificar que no se trata de una vertiente de la dialéctica del dandi que propuso Baudelaire y que trata también Walter Benjamin en relación al poeta francés, sino más bien de la dialéctica del guerrillero o revolucionario que han sugerido Ileana Rodríguez y María Josefina SaldañaPortillo.

$\begin{array}{lllrlr}\text { Revista Iberoamericana, Vol. LXXIX, Núm. 242, } & \text { Enero-Marzo 2013, } & \text { 57-74 } \\ \text { ISSN 2154-4794 (Electrónico) }\end{array}$ 
Sandino como líder de resistencia, sino por ser una de las que más ha circulado y por ser más compuesta a nivel formal.

Siguiendo la tradición histórico-materialista y estructuralista, la propuesta analítica de Roland Barthes en torno a la imagen como objeto de estudio establece ciertas pautas provisionales metodológicas. Según el crítico francés, las estructuras propias de la imagen fotográfica encierran la clave de su mensaje: "Without in any way intending to divorce this object from its use, it is necessary to provide a specific method prior to sociological analysis and which can only be the immanent analysis of the unique structure that the photograph constitutes" (15-16). El análisis sociológico de Barthes se refiere a lo relacionado con la producción, emisión y recepción de la imagen fotográfica, con lo que haré muy pocas referencias a estos detalles, para más bien enfocarme en el mensaje visual. ${ }^{4}$ No obstante, me parece importante problematizar la propuesta de Barthes y tener en cuenta también el planteamiento que hace W.J.T. Mitchell en cuanto a la dificultad de establecer una relación crítica con las imágenes fotográficas. Según Mitchell, el poder de los imaginarios visuales, sobre todo los fotográficos, se debe a que los seres humanos mantenemos una relación de doble conciencia con éstos, la que oscila entre actitudes tradicionales como la idolatría, el fetichismo y el totemismo, versus una postura de escepticismo y de distancia crítica (8). Presento también este último planteamiento para contrarrestar la pretensión totalizante y objetiva de la crítica inmanente, y para ir sugiriendo cómo se desdobla esa doble conciencia en la aproximación a las imágenes fotográficas de un héroe nacional.

Quizás sea precisamente desde dicho desdoblamiento de la conciencia que surjan dudas en torno a esta imagen fotográfica, específicamente que el sujeto parezca vacilar entre la representación de un dandi cosmopolita por la pulcritud del traje y el rostro bien

4 En el contexto moderno, esta imagen se presenta en por lo menos tres lugares públicos fuera del marco nacional: primero en la sección de "El tiempo contemporáneo" de un libro de turismo titulado Nicaragua, publicado por el Banco Central de Nicaragua en 1996 bajo la presidencia de Arnoldo Alemán. Tres años después aparece en la portada del estudio titulado Sandino: una biografía política, escrito por Volker Wünderich (la misma edición referida en esta bibliografía).Y ahora la imagen también se encuentra ampliamente diseminada en internet (por ejemplo en Wikipedia). A principios de 1980 una réplica en pintura en tamaño natural de esta imagen fotográfica aparece en la entrada del Museo de Héroes y Mártires de Masaya, haciendo resaltar no sólo el vínculo entre Sandino y los mártires de la revolución como extensión de la misma lucha, sino también el protagonismo fundacional del mismo en ese espacio conmemorativo. El contraste entre este mural, una composición formal que conlleva la imagen de Sandino, y las imágenes fotográficas cándidas de los mártires contemporáneos, apunta a una maniobra interesante de la rearticulación de un elenco histórico de lucha y resistencia. Pese a que se trataba de un museo poco convencional, la adaptación de la imagen de Sandino a pintura parece cumplir con el protocolo de mantener la forma del museo en su sentido clásico. El fotógrafo Antonio Turok también habrá percibido cierta ironía y el meta-mensaje de esa transformación puesto que en su libro Imágenes de Nicaragua la portada es precisamente una fotografía de esta imagen.

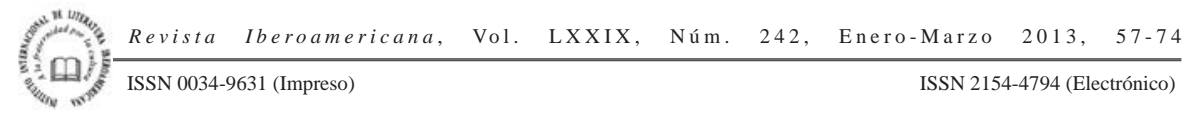


afeitado o un revolucionario mexicano por el sombrero, las botas y la bandolera. Por otra parte, una interpretación esotérica de la imagen enfatizaría las cualidades místicas y mesiánicas de Sandino, reinscritas en esta imagen debido a la forma del telón de fondo -a la derecha del marco- que parece aludir a un monje fantasmagórico rezando, cuyas manos se encuentran a la altura de la cintura del sujeto. Un analista freudiano o el connoisseur de tabaco también aportarían una interpretación interesante sobre esta imagen. Esta serie de posibilidades enmarca la lectura histórica y crítica que aquí propongo. Teniendo en cuenta que la pose está encuadrada dentro de los objetos del atrezzo, empezaré por la pose del hombre de y en resistencia.

\section{ASUMIENDO UNA POSE DE RESISTENCIA}

La pose de Sandino en esta imagen fotográfica corresponde al género del retrato de estudio, una práctica clave de representación social. En el contexto de finales del siglo xIx y la primera mitad del siglo xx, este espacio privado-comercial le permite al sujeto (re)presentarse tal y como quiere ser visto, o mejor dicho, recordado. En este sentido el retrato de estudio puede definirse como un escenario para el performance del recuerdo. El acto de materializar el memento va orquestado por el fotógrafo, quien dicta los términos generales de la pose según las necesidades de iluminación y otras convenciones relacionadas con las prácticas de la mirada. El esmero del fotógrafo por arreglar y fingir la naturalidad de la pose del sujeto produce precisamente el efecto opuesto, es decir, el arreglo excesivo del retrato que le hacen reproducir la estética de un cuadro (Kracauer 19). Más adelante me referiré a las implicaciones, en este caso, del gesto publicitario y del acto autobiográfico de ir a una sesión fotográfica en un estudio para proyectar una imagen determinada. Pero lo menciono precisamente aquí para tener en cuenta el contrapunto entre la pose y el gesto en relación a la proyección de la subjetividad "revolucionaria".

La pose y los objetos del atrezzo obedecen, por una parte, a la lógica de la pose y, por otra, a una convención fotográfica decimonónica. Esta convención responde a que el sujeto tiene que mantener la pose para cumplir con la necesidad técnica de la velocidad de obturación. Originalmente la limitación técnica se superaba con ciertos objetos, tal y como una mesita, una silla o una columna que le permitía al sujeto mantener la pose. Sin embargo, este tipo de pose, explica Walter Benjamin, pese a los avances tecnológicos se ha mantenido para enmarcar y presentar en términos auténticos a la nueva clase social que puede permitirse el lujo de retratarse. Es decir, el retrato como práctica social se ocupa de representar de forma convencional una nueva clase social, la cual simula su aura con los retoques, los accesorios y la producción elaborada decimonónicamente. El propósito de esta simulación, según Benjamin, es permitirle a la nueva clase social legitimar y materializar su lugar en la escala social (517). Sin embargo, aquí se trata no

\footnotetext{
Revista Iberoamericana, Vol. LXXIX, Núm. 242,
ISSN 0034-9631 (Impreso)
} 
necesariamente de una nueva clase social, sino de un nuevo agente histórico. La pregunta es cómo entonces se representa la resistencia nacional dentro de estas convenciones sociales pequeño-burguesas.

Roland Barthes explica que la pose revela "una gramática histórica de connotación iconográfica” cuyo contenido se encuentra en la cultura (22). El desafío de la mirada, en conjunto con el ángulo de los pies y la mano en la cintura que aquí parece enfrentarse la cámara, y por ende al espectador, subvierte la convención del retrato como memento del recuerdo. Ésta no es la representación de un novio, hijo o amigo que deja constancia de su imagen a un ser querido. El porte que capta este retrato, además de vanidad, denota obligación, impaciencia e imposición. La mirada de determinación de Sandino y el aire de desafío pueden ser interpretados como parte de la historia que anticipa. La teatralidad de la pose, aparentemente neutralizada por la inclinación contra la mesita, se enfatiza a través del uso del puro, un puro que al estar posicionado a nivel de la cintura, adquiere una connotación fálica. En este retrato de Sandino la pose masculina tradicional que finge naturalidad se facilita por el tableau, permitiéndole al sujeto reclinarse con el pretexto del puro y así colocar su otra mano en la cintura. Esta treta de disimulo de naturalidad pone de realce la actitud antes mencionada de espera, anticipación e indignación.

El gesto de ir a un estudio para proyectar su imagen y dejar constancia material de su apariencia es parte de la pose; no de la pose específica del retrato, sino de la pose abstracta/general de querer personificar la épica de una lucha de liberación nacional. La fotografía es una herramienta clave para proyectar y definir las representaciones modernas de la subjetividad. Dicho en otras palabras, la fotografía es parte del acto moderno de auto-representación (Rugg 4). En este caso, la pose abstracta y específica apunta a una imagen que pretende desbordar la subjetividad individual para darle cara a una resistencia colectiva y a la soberanía nacional. De la misma manera, capta el gesto de querer inscribir ese esmero individual para la posteridad de la historia nacional y continental. Asimismo, los objetos del atrezzo, además de responder a la lógica de la pose, se convierten en códigos de esa resistencia.

\section{El Puro}

Guerrillero y dandi, actor y vaquero: una sola imagen capta las capas y convergencias de múltiples discursos, forjando y truncando las normas de representación. Por ejemplo, aquí el puro -forma rústica de la masculinidad burguesa- sustituye al cigarrillo o a la pipa, propios del dandi europeo como objeto de atrezzo del retrato. Además o quizás como parte de las connotaciones fálicas, el puro es un símbolo de status, poder y ocio que materializa en su propia forma la historia de conquista y de imperio. En esta imagen el puro sirve para establecer la unidad de la composición fotográfica puesto que ancla la

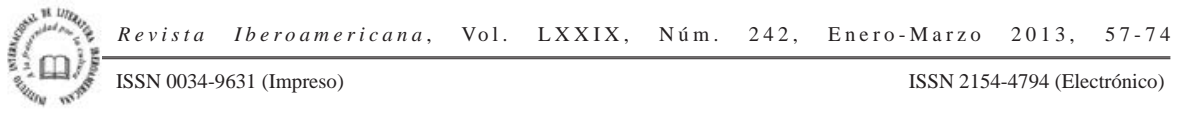


pose. La otra mano lleva la mirada a la ristra de balas, aludiendo, a través de la relación del cuerpo con los objetos del atrezzo, al humo y al fuego, es decir, a la lucha.

Por otra parte, el puro presenta a un nuevo sujeto social e histórico al margen de la convención. Aquí esta representación produce un efecto uncanny o aurático, puesto que anticipa y evoca a las representaciones clásicas de Ernesto “Che” Guevara y Fidel Castro, íonos de la Revolución Cubana. En este sentido, en el retrato de Sandino el efecto aurático se produce además mediante la nostalgia que implica el blanco y negro. Si, como acierta a decir Walter Benjamin, los detalles de la composición fotográfica nos permiten una aproximación al "inconsciente óptico de la historia” (511-12), entonces esta imagen fotográfica nos lleva directamente a la pregunta freudiana del millón: ¿es un puro sólo un puro?

Aunque aquí, y en otras imágenes fotográficas de Sandino, el sujeto posa con un puro, existe una contradicción biográfica entre esta representación y las supuestas prácticas de consumo del sujeto. Según la construcción pública del "general de hombres libres”, éste era abstemio y no fumador. Esta contradicción se anticipa en la imagen por la boquilla que intermedia entre las manos del sujeto y el puro. El puro con boquilla fue una costumbre aristocrática inglesa. Fumar puro también se reserva para marcar alguna ocasión especial, incluso para los hombres que no practican el hábito del tabaco. El atuendo más distintivo del dandismo es un cigarrillo con boquilla o una pipa. Entonces el puro con boquilla aquí recalca la hiper-teatralidad de la composición fotográfica, problematizando la iconografía del dandi y la del revolucionario.

El puro en esta imagen fotográfica desafía otro aspecto de la iconografía revolucionaria latinoamericana. A diferencia de las imágenes de la Revolución Cubana: aquí el puro está entero, sin consumirse. Es así que el puro aporta un toque teatral, apuntando a la pretensión de una masculinidad refinada. ${ }^{5}$ Por el contrario, las imágenes de Fidel Castro y Ernesto "Che" Guevara muestran al sujeto revolucionario fumando, produciendo humo, consumiendo el objeto entre manos, como parte de la imagen pública que estaban proyectando. Superficialmente, las imágenes de los revolucionarios fumando se insertaban en la esfera de la farándula de Hollywood, remitiéndolos a la cultura visual popular. En el plano simbólico, el gesto de fumar un puro, como parte de su construcción revolucionaria, implicaba reclamar y retomar la producción nacional del tabaco, como uno de los “contrapuntos” de explotación de la economía cubana. En las representaciones

5 Comentando el trabajo de Ileana Rodríguez sobre la feminización de los sujetos guerrilleros, María Josefina Saldaña-Portillo elabora el tema de la androginia revolucionaria en los escritos del Che. Dicha androginia textual se presenta dialécticamente a la caracterización física del mismo (79). En el caso de Sandino mi argumento sería a la inversa, es decir que sus escritos insisten en una autoridad patriarcal, pero que su configuración y autoconstrucción física apunta a cierta androginidad que corresponde a un modelo pequeño burgués de masculinización femenina.

Revista Iberoamericana, Vol. LXXIX, Núm. 242,
ISSN 0034-9631 (Impreso) 
clásicas de Castro y de Guevara el puro se consume, se fuma, suponiendo el poder adictivo del hábito. Irónicamente esta connotación visual es consistente con los patrones de consumo de los souvenirs con las imágenes de Guevara, cuya especificidad histórica ha sido alterada y modificada para convertirse en referente y mercancía de resistencia. ${ }^{6}$

\section{EL SOMBRERO Y OTROS ARTEFACTOS DE RESISTENCIA}

El ángulo de los pies en combinación con las botas acentúa el gesto de expectativa y agresividad, anticipado por la mirada directa de Sandino hacia la cámara. Otros accesorios como la ristra de balas a la cintura, el pañuelo al cuello, la insignia en la solapa -probablemente de la escuela Magnético Espiritual de la Comuna Universal de Joaquín Trincado ${ }^{7}$ - codifican la legitimidad de su resistencia, enfatizándola con la pulcritud del traje. El arma está insinuada, cubierta por la solapa del traje, para que de esta manera las convenciones del dandi velen al guerrillero. Fiel a la fórmula de vestir de Sandino, los pantalones kakis metidos dentro de las botas al estilo cavalier, cumplen con una práctica militar de vestimenta requerida por la convención, por las condiciones topográficas y por las prácticas de la lucha armada. Junto con éstos, los signos iconográficos relacionados con Sandino, los lapiceros disimulados en el pecho, fueron otras de sus armas más efectivas. ${ }^{8}$ Sin embargo, el indicador más importante de su lucha ha sido su sombrero Stetson, el cual, a partir de 1979, vendría a ser un símbolo metonímico de su resistencia y del movimiento sandinista.

6 Además de las camisetas, pósteres y tarjetas postales que se venden con la imagen de Guevara en la mayoría de los mercados latinoamericanos, me parece interesante el uso que hizo el conjunto Rage against the Machine de la imagen de Guevara, convirtiéndolo en el ícono del grupo. Aunque para la mayoría de los seguidores del grupo se perdía el referente histórico del sujeto revolucionario, la música de este grupo multicultural y militante de los años noventa de Los Ángeles mantenía la imagen de Guevara dentro de los registros de resistencia. Por ejemplo, la imagen del Che aparece en la portada del single "Bombtrack" y en la mercancía relacionada con este tema, además de encontrarse entre otras figuras de resistencia en la página oficial del grupo. Por otra parte, en vez de la típica boina, en respuesta al 9/11, el artista brasileño Carlos Latuff produjo una imagen de Guevara con la Kufiyya. Esta relación entre la causa palestina y la de Che Guevara se estableció de manera inmediata a partir del incidente de Leyla Kaheled, que llevó a la producción de pósteres, carteles y panfletos que unían la imagen de Kaheled con la de Guevara en una misma esfera (Leyla Kaheled pertenece al Frente Popular de Liberación Palestina y fue la primera mujer en secuestrar un avión en 1969 para reclamar la atención pública sobre la causa palestina).

7 Joaquín Trincado fue un emigrante vasco en Argentina y fundador de la escuela Magnético Espiritual de la Comuna Universal (EMECU). Los ideales de dicha organización combinaban ideas anarquistas con el espiritismo, la kabbalah y el zoroatstrianismo. Sandino fue discípulo de la EMECU, consolidando su aproximación a la misma en su segundo viaje a México. Los detalles de esta faceta ideológica de Sandino aparecen bien articuladas en el estudio de Donald Hodges.

8 Entre 1927 y 1933 Sandino publica doce manifiestos, además de múltiples declaraciones, cartas y entrevistas. Los escritos de Sandino aparecen recopilados en dos tomos de una colección de Sergio Ramírez, titulada El pensamiento vivo.

\footnotetext{
$\begin{array}{llllll}\text { Revista Iberoamericana, Vol. LXXIX, Núm. 242, } & \text { Enero-Marzo 2013, } & \text { 57-74 } \\ \text { ISSN 2154-4794 (Electrónico) }\end{array}$
} 
Stetson es una de las marcas más famosas de sombreros de vaqueros, utilizados también durante la Revolución Mexicana en el norte de México como alternativa al sobrero charro. Francisco (Pancho) Villa -a diferencia de su homólogo sureño Emiliano Zapata, quien nunca sustituyó su charro-, más de una vez utilizó también un ejemplar parecido. Por su parte, Augusto C. Sandino regresó a Nicaragua después de su primera estadía en México (1921-1926) ya con el sombrero Stetson, adquiriéndolo quizás en México mismo o en su travesía por Honduras y Guatemala. Este tipo de sombrero Stetson se convertiría en un signo de masculinidad nacionalista en Centroamérica, puesto que Farabundo Martí, después de su regreso de México a El Salvador, también anduvo con uno parecido hasta su muerte. Sin embargo, a diferencia de Sandino, la masculinidad revolucionaria de Farabundo Martí mantuvo signos consistentes con la iconografía de la Revolución Mexicana en cuanto al bigote. El vello facial, ya sea en forma de bigote 0 de barba, ha sido referente de resistencia latinoamericana, empezando con la Revolución Mexicana y culminando con la Revolución Cubana. Incluso posteriormente, la mayoría de los líderes del Frente Sandinista de Liberación Nacional (FSLN) también utilizaron el bigote. La excepción de Sandino en cuanto a este signo de masculinidad puede ser una referencia étnica que enfatiza su identidad indígena, aunque también puede verse como una forma de conformación a la masculinidad refinada que a su vez apunta al carácter nacionalista y no necesariamente "revolucionario" de su lucha.

Retomando el tema del sombrero Stetson, éste se denomina también sombrero de galón. ${ }^{9}$ El uso del sombrero en Estados Unidos, sobre todo en el Oeste, es indivisible de la historia común entre dicho país y México, que, marcado por la influencia española, ya había creado su propia versión: el sombrero charro. Sin embargo, a medida que Estados Unidos expandía su frontera hacia el Oeste, el sombrero fue cogiendo su propia forma hasta culminar con el modelo Stetson. Además de su propósito funcional, este tipo de sombrero inscribe la masculinidad y connota la expansión de Estados Unidos hacia el Suroeste, convirtiéndolo en un signo de esta zona fronteriza. Al usar este tipo de sombrero, Sandino y Martí inadvertidamente tropicalizan el referente del Sureste de Estados Unidos, descodificando representaciones de poder a la vez que expandían el imaginario de la frontera estadounidense hasta el centro del Istmo. Éstas son implicaciones sugerentes, si recordamos que la lucha de Sandino era precisamente en contra de la intervención militar estadounidense en su país. En esta imagen fotográfica la mitificación de su lucha se delinea por la sombra que produce el sombrero en la cara del sujeto.

Eventualmente, las imágenes de Sandino vendrían a reemplazarse por el contorno del sombrero. Por consiguiente, el símbolo metonímico capta y anticipa el fetichismo y la teatralidad de la resistencia, de la masculinidad y de la militancia. Mucho después

9 Sobre la importancia social e histórica de este tipo de sombrero, referirse al artículo de Peter Tamony.

$\begin{array}{llllll}\text { ISTN 2154-4794 (Electrónico) } & \text { Iberoamericana, Vol. LXXIX, Núm. 242, }\end{array}$ 
de su muerte, con el triunfo de la Revolución Sandinista, el contorno del sombrero se fragua entre 1979 y1990 como un ícono propio de ese período histórico de resistencia, plasmado en las paredes de Nicaragua. ${ }^{10}$ De cierta forma el uso del sombrero, vacío de su portador, en el imaginario popular visual de la primera época Sandinista reproduce el uso vacío del nombre de Sandino en el Frente Sandinista de Liberación Nacional. ${ }^{11}$ Puro y sombrero: entretenimiento, anuncio y propaganda, hechos en México, Cuba y en Estados Unidos, se convierten en los códigos de resistencia latinoamericana.

LA PLATAFORMA MEXICANA Y LA RED CENTROAMERICANA

Como ya he mencionado, esta imagen fotográfica de Sandino se produce en Yucatán, en 1929, durante su segunda estadía en México; su primera estancia mexicana había sido de 1923 a 1927. El primer viaje de Sandino a México no se produce por razones políticas, como vendría a ser el caso de Farabundo Martí, sino más bien para evitar problemas en su país por una disputa que tuvo en Nicaragua con un Dagoberto Rivas en 1921 (Wünderich 41). Sandino experimenta la realidad proletaria por primera vez en su ruta a Yucatán, tras trabajar para compañías multinacionales estadounidenses en Honduras, Guatemala y el propio México. Entre estas empresas se encuentra el Ingenio de Montecristo de la Honduras Sugar and Distilling Company, y la United Fruit Company. Al llegar a Tampico, México, trabaja para la South Pennsylvania Oil Co., y luego para Huasteca Petroleum (Wünderich 48-50). Estas experiencias le permitieron presenciar los mecanismos de dependencia del sistema capitalista de la producción de materias primas en la cuenca caribeña, es decir, la producción de la fruta y el petróleo. Esa experiencia histórica (pre)industrial y multinacional fue decisiva para el contenido biográfico que sustentó su lucha. Su primera estadía de tres años en México fue clave para la formación política e intelectual de Sandino, ya que se llevó a cabo cuando aún hervía el fervor de la Revolución Mexicana y se gestaba la Guerra Cristera. La primera estadía de Sandino en México coincide con el auge de la rearticulación de la identidad posrevolucionaria mexicana, definida en la rama cultural por figuras como José Vasconcelos y Diego Rivera. En términos políticos, Sandino presencia las polémicas nacionales en torno a las propuestas de leyes como la de trabajo y la agraria que predica Álvaro Obregón. ${ }^{12}$

10 El libro de Joel Sheesley documenta fotográficamente las adaptaciones de la imagen de Sandino y su uso en las calles de Nicaragua. El libro demuestra los distintos medios en que aparece la imagen de Sandino y también ilustra el uso de la silueta del sombrero en los espacios públicos.

11 Cabe recordar que Carlos Fonseca Amador funda el FSLN después de haber viajado a Cuba durante su auge revolucionario. Él se encarga de reinsertar la figura de Sandino en el imaginario intelectual de resistencia nicaragüense en dos textos: Ideario político de Augusto César Sandino y Sandino: guerrillero proletario.

12 Sobre la experiencia de Sandino en México, referirse al estudio de Carlos Castilla Villanueva.

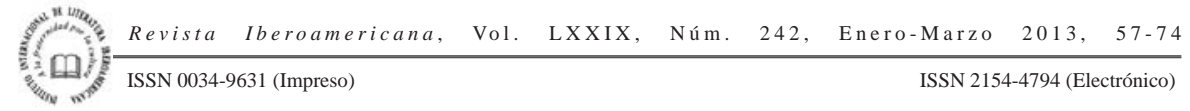


Al llegar a México por primera vez, Sandino se vio sumergido en lo que quedaba del impulso revolucionario. Era la época en la que los líderes locales mexicanos, sobre todo Calles y Obregón, competían por nacionalizar la industria petrolera. Sandino se politiza y radicaliza durante estos tres años (1923-1926) en la península de Yucatán, presenciando directamente la formación del movimiento sindicalista y agro-comunista de la región. Durante su estadía en México el nicaragüense asimila un tipo de conciencia anarco-comunista, retomando de los anarquistas españoles el rojo y negro como insignia de "libertad o muerte", credo principal de su lucha armada. También en México se apropia de la bandera con un esqueleto aparentemente pirata, que había sido tomado como símbolo en la causa de Pancho Villa. ${ }^{13}$ El collage icónico y retórico que Sandino asimila durante este período mexicano pone en tela de juicio la coherencia ideológica que sustentó su lucha.

El modelo social que Sandino encuentra en México lo inspira en parte a regresar a Nicaragua en 1926 y tomar armas en contra de la intervención estadounidense. Ese mismo año se incorpora al ejército Liberal para luchar en la llamada “Guerra Constitucionalista”. Dicha guerra (1926-1927) fue un gesto de resistencia lanzado por el Partido Liberal, supuestamente para defender los abusos hacia la constitución de Nicaragua, fomentados por los intereses militares estadounidense y ejecutados por políticos locales. No obstante, una vez que el líder liberal -José María Moncada- obtiene un puesto de poder en el proceso de reconstrucción estatal, él abandona la lucha, firmando en 1927 el tratado de Tipitapa con los representantes de las fuerzas estadounidenses. Sandino renuncia la resistencia formal en mayo de 1927. Dada “la traición del partido liberal”, Sandino se niega al desarme y en julio de ese mismo año lanza su primer manifiesto público dirigido “[a] los nicaragüenses, a los centroamericanos, a la raza indo hispana”. ${ }^{14}$ En septiembre de ese año funda su propio ejército, el Ejército Defensor de la Soberanía Nacional Nicaragüense (EDSNN). A partir de su primer manifiesto, Sandino empieza a construir una imagen pública discursiva que alcanzaría su forma visual en el retrato aquí referido. En la narrativa histórica que construye en sus manifiestos, se auto-asigna el protagonismo épico que requiere de una historia ficcionalizada que se proyecta en esta imagen. ${ }^{15}$

En esta primera etapa (1927-1929) de la lucha de Sandino, antes de su segundo viaje a México, el nicaragüense depende de una red de apoyo centroamericano que incluye un componente discursivo y otro de praxis. El encargado de ese primer componente fue Froylán Turcios, escritor y periodista hondureño que se ofreció a ser secretario

${ }_{13}$ Sobre el simbolismo icónico de la lucha de Sandino, referirse también a Alejandro Bolaños Geyer.

${ }^{14}$ Según Wünderich, la tesis de indo-hispanismo proviene del fundador de la Alianza Popular Revolucionara Americana (APRA), el peruano Víctor Raúl Haya de la Torre y del intelectual mexicano José Vasconselos (80). Puede consultarse el manifiesto en <http://acugragranada.codigosur.net/leer.php/2714034> .

15 Para un análisis sobre el elemento literario en los manifiestos de Sandino, véase el artículo de Medina.

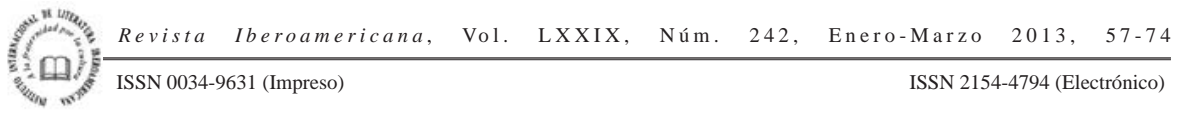


personal de Sandino, y que con su revista Ariel sirvió de portavoz de su causa. En dicha publicación Turcios publicó comunicados, partes de guerra y misivas pertinentes entre él y el hombre de acción, dándole así una plataforma discursiva, pese a la lucha rural que estaba efectuando. El título de la revista resulta interesante ya que hacía hincapié en el americanismo de Rodó y circunscribía el Modernismo y el dandismo mientras se desplegaba en su contenido la militancia nacionalista. Este espacio discursivo fue imprescindible para la diseminación de las ideas y las acciones de Sandino, del mismo modo que permitió insertarlo en la red intelectual centroamericana. Este intelectual amateur también se entrevé en esta representación de Sandino en el retrato. ${ }^{16} \mathrm{El}$ componente de la praxis en la red de apoyo centroamericano es aportado por Agustín Farabundo Martí, quien en 1928 se incorpora a la lucha armada de Nicaragua. ${ }^{17}$ Sin embargo, estas redes de apoyo fueron frágiles y para 1930 ambas ya estaban deshechas. La primera ruptura fue entre Turcios y Sandino en 1928. Los motivos de este distanciamiento siguen siendo hoy motivo de debate; sin embargo, este hecho fue determinante para la trayectoria de la lucha anti-imperialista porque al verse desconectado de una plataforma discursiva Sandino se vio obligado a buscar una forma alternativa de proyectar y dar a conocer su causa.

Tras la revolución, México se había convertido en un epicentro de encuentros y en un laboratorio de cambio social; donde, por ejemplo, Trotski se refugia del bolchevismo y se encuentra no sólo con Frida Kahlo y Diego Rivera, sino también con André Breton. México también era destino de una ola de exiliados españoles que cambiarían el panorama intelectual local, entre ellos Luis Buñuel; era el mismo lugar donde pocos años después un doctor argentino se encontraría con el joven cubano Fidel Castro para lanzar desde ahí una revolución que cambiaría para siempre la dinámica política del hemisferio. Coincidiendo con el desplome de la bolsa, con la ruptura con Turcios y con la aprobación de la creación de la Guardia Nacional en Nicaragua, en 1929, dos años después de haber empezado su lucha, Sandino regresa a México, a ese lugar familiar de reconstrucción revolucionaria para rearticular su imagen. A diferencia de su primer viaje anónimo, esta vez Sandino llega acompañado por la comitiva internacional de su “Estado Mayor”, entre ellos Farabundo Martí, de quien se distancia durante esta gira

${ }^{16}$ La categoría de "intelectual amateur" la define Edward Said refiriéndose a los individuos no especializados que cuestionan cierto aspecto de la realidad por sus convicciones propias (76).

${ }^{17}$ Aunque aquí he enfatizado el aporte de Turcios y Martí, evidentemente esa red de apoyo incluyó a muchos participantes más de Centroamérica y de otros países hispanoamericanos, como también otros mecanismos de ayuda como los comités pro-Sandino en Costa Rica dirigidos por Joaquín García Monge y Manos Fuera de Nicaragua (MFUENIC) en México, el cual contó con la participación del revolucionario cubano José Antonio Mella y de los artistas David Alfaro Siqueiros, Diego Rivera y Frida Kahlo. Sandino llegó a denominar a los voluntarios dedicados a su causa Legión Latinoamericana, la cual estaba compuesta por representantes de muchos países latinoamericanos (ver Hodges, Torres y Wünderich).

$\begin{array}{llllll}\text { Revista Iberoamericana, Vol. LXXIX, Núm. 242, Enero-Marzo 2013, } & \text { 57-74 } \\ \text { ISSN 2154-4794 (Electrónico) }\end{array}$ 
publicitaria. Es ese desencuentro el que enfatiza el carácter nacionalista de su lucha, perdiendo efectivamente cualquier fachada de una movilización de clase.

Al igual que la paradoja representativa que aparece en la imagen fotográfica, el marco ideológico de Sandino es una labor en retazos variados de las corrientes que circulaban en México en esa época. La obra del anarquista Flores Magón y el místico Joaquín Trincado fueron las que más influencia tuvieron en el centrifugador ideológico de Sandino durante esta segunda estadía en México. Ya he hecho referencia a los discursos de identidad de José Vasconcelos en su adaptación de la raza indo-hispana; cabe mencionar dentro de esta constelación de pensadores que influyeron a Sandino a Alberto Masferrer, filósofo salvadoreño de la época. ${ }^{18} \mathrm{~A}$ diferencia de la proyección posterior que se ha hecho del pensamiento de Sandino hacia el comunismo y el socialismo en el imaginario político nacional, según los especialistas académicos, como por ejemplo el pionero Gregorio Selser y luego Donald Hodges y Volker Wünderich, las dos tendencias dominantes de su base ideológica fueron el anarquismo y el espiritismo. ${ }^{19} \mathrm{Como}$ parte de las adaptaciones de la imagen, de su nombre y de su ideología, es preciso observar que este elemento esotérico y mítico que marca los escritos de Sandino empezó a suprimirse a partir de la secularización que produce la Revolución Cubana y la subsiguiente formación del FSLN encabezada por Carlos Fonseca Amador (Zimmerman 145). Al igual que Zimmerman, Wünderich argumenta que el proceso de esta transformación enfatiza la retórica de clase y nacionalista de Sandino mientras que suprime el indiscutible discurso místico y esotérico de su obra (52).

Consecuente con el mosaico ideológico de las doctrinas revolucionarias, la afinidad de Sandino con el comunismo surge no a través de marxismo ortodoxo, sino más bien por la influencia de las revoluciones francesas de 1830 y 1848. El análisis de Hodges sobre el pensamiento de Sandino traza su genealogía ideológica de manera sistemática, remontándola a la tradición de pensadores como Auguste Blanqui, Pëtr Kropotkin, Errico Malatesta, Pierre Joseph Proudhon, Ricardo Flores Magón y -dentro de ese contexto heterodoxo- Vladimir Lenin (10). La imagen fotográfica refleja la discordancia entre este discurso ideológico, la identidad del sujeto y la pose junto a los objetos de atrezzo. Contribuyendo a esta ambivalencia, el rostro lampiño lo distancia de la masculinidad iconográfica que caracteriza a los líderes de la Revolución Mexicana y posteriormente de la cubana.

${ }^{18}$ Sobre la relación implícita y explícita entre Masferrer y Sandino, referirse al estudio de López Bernal.

19 En el esmero por definir a la figura histórica, cabe señalar que existe una serie de "estudios” y biografías políticas de Sandino que borran y eliminan cualquier posible afinidad ideológica para apuntar a patologías psicológicas y sociales que explican su supuesto delirio de protagonismo. Esta línea de argumento empieza con el texto de Anastasio Somoza García, los de Alejandro Bolaños Geyer y el de Marco Navarro-Génie. Por otra parte, también hay una serie de biografías que mitifican a Sandino en términos esotéricos.

Revista Iberoamericana, Vol. LXXIX, Núm. 242, Enero-Marzo 2013, $57-74$
ISSN 2154-4794 (Electrónico) 
Pese a no haber recibido el reconocimiento ni la ayuda que esperaba del gobierno mexicano, esta campaña publicitaria en Yucatán no fue un fracaso total, ya que le otorgó una plataforma difusora de su lucha y de su imagen. Durante su estadía, que a veces parecía ser una forma de exilio y/o prisión, además de publicar un manifiesto en el Diario de Yucatán, concedió un sinnúmero de entrevistas, permitiéndole dar a conocer su causa en los periódicos locales. ${ }^{20}$ Constatando su afiliación con la sociedad secreta, Sandino deja en la logia parte del archivo del Ejército Defensor de la Soberanía Nacional Nicaragüense. En este segundo viaje Sandino también consolida su incorporación a circuitos masculinos de influencia como la logia masónica, a la cual se adhiere junto a Martí antes de su ruptura con él. También formaliza su relación con la EMECU de Trincado, afiliación que llegaría a marcar y cambiar la trayectoria de su pensamiento político tal y como se presenta en sus escritos posteriores, partiendo de su manifiesto "Luz y verdad".

En este segundo viaje a México, Sandino consolida sus lazos con los circuitos masculinos sociales y también internacionaliza su lucha. No obstante, no obtuvo el resultado inmediato que esperaba, puesto que no se le concedió audiencia inmediata con el presidente interino mexicano Emilio Portés Gil, pasó algunos días en la cárcel y tuvo que regresar a Nicaragua con las manos vacías. Sin embargo, los efectos y motivos que llevan a este movimiento regional, de Nicaragua a México, delinean un triángulo más amplio de diplomacia entre Centroamérica, México y Estados Unidos. México sirve no sólo de plataforma de socialización y proyección internacional para el sujeto "revolucionario" centroamericano, sino que también actúa como intermediario y amortiguador de la hegemonía política de los Estados Unidos y el Istmo.

La complejidad de la relación entre México y Centroamérica, ya determinada por la contingencia geopolítica y su historia común, se encuentra materializada y plasmada no sólo en la producción material, sino también en las connotaciones de la imagen. Dentro del marco de la historia geopolítica, para la subjetividad intelectual/de resistencia centroamericana, México ha servido como plataforma de profesionalización y politización. De la misma manera, a nivel regional México ha sido un campo de entrenamiento para la construcción de las naciones centroamericanas que definieron su independencia de la federación. Es más, México ha cumplido con ser la metrópolis regional, donde en este caso Sandino no sólo formuló su marco ideológico, sino también reconfiguró su modo de auto-representación en signos, no sólo textuales, sino que también visuales y dialógicos. A través de sus experiencias mexicanas, Sandino sintetiza una convergencia de influencias que incluyen el legado de la Revolución Mexicana, la experiencia anarcocomunista española, el legado masónico y el espiritismo/misticismo argentino. Esta

${ }^{20}$ Pese a ser dirigido a los nicaragüenses, dicho manifiesto se publica el 6 de septiembre de 1929 en el Diario de Yucatán (Sandino 1/387).

$\begin{array}{lllll}\text { ISSN 2154-4794 (Electrónico) } & \text { Revista Iberoamericana, Vol. LXXIX, Núm. 242, }\end{array}$ 
imagen fotográfica es un artefacto de historias sociopolíticas que proyecta todos estos discursos. Se trata de una forma visual de intervención, un espacio fronterizo de conflicto que se despliega en el dominio de la cultura popular. La trayectoria biogeográfica de Sandino establece la importancia de México como plataforma de consolidación para el sujeto revolucionario y nacional centroamericano, puesto que, como sabemos, su formación ideológica se construye durante sus estadías mexicanas en el contexto de la reconstrucción posrevolucionaria. Otros sujetos de resistencia que seguirían una trayectoria parecida serían el mismo Farabundo Martí y, en otros contextos, Mario Payeras y Roque Dalton.

\section{ENMARCANDO EL RETRATO}

Como bien sabemos, Sandino regresa a México en 1929 para recaudar apoyo para su lucha armada en contra de la ocupación militar estadounidense en Nicaragua. ${ }^{21} \mathrm{La}$ intervención de Sandino ante las pretensiones hegemónicas de Estados Unidos define las pautas de resistencia impulsadas por el nacionalismo. Grandin explica que las tácticas de guerrilla de Sandino le mostraron al ejército estadounidense que el nacionalismo político es una fuerza potente, y que, pese a la asimetría militar existente, Nicaragua le supuso su primer atolladero del Tercer Mundo. Es decir que Nicaragua fue para Estados Unidos parte intrínseca del taller o laboratorio de su imperio, en el sentido militar (31). Aunque queda por aclararse si la fuerza que impulsó a Sandino fue patriotismo o nacionalismo, dicha fuerza, o como queramos llamarla, sigue de manifiesto en su legado e imágenes, acogiendo otras formas y referentes en lugares como Cuba, y sigue desenvolviéndose hoy en día en Nicaragua. Para exponerse como personificación del patriotismo y de la soberanía nacional, Sandino supo formular un arsenal simbólico que incluía manifiestos, comunicados, entrevistas y también imágenes fotográficas.

Este retrato es evidencia de lo dicho y marca su retorno a México como líder político en busca de solidaridad y apoyo, promoviendo su causa y un culto en torno a su figura. La sesión fotográfica que produce este retrato fue parte de una campaña publicitaria y de un gesto que pretendía darle una cara pública y legítima a su lucha, que a la vez refutó la imagen de bandido que los medios estadounidenses y nicaragüenses diseminaban. ${ }^{22}$ No obstante, según mi investigación, este retrato en particular no fue publicado en su momento. Además de la aparente falta de diseminación dentro de su propio contexto, es interesante que esta imagen tampoco circulara en vísperas del triunfo de la revolución

${ }^{21}$ Dicha ocupación había empezado en 1909 y duraría de forma directa hasta 1933 -con un hiato simbólico entre 1926-1927-, convirtiéndose en la ocupación militar consecutiva más duradera por parte de Estados Unidos (Selser 10).

22 Sobre la retórica del bandido y las distintas estrategias narrativas de deslegitimación respecto a las luchas de "liberación nacional”, véase el artículo de Michael J. Schroeder.

$\begin{array}{llllll}\text { ISSN 2154-4794 (Electrónico) } & \text { Revista Iberoamericana, Vol. LXXIX, Núm. 242, }\end{array}$ 
de 1979 en los periódicos dedicados a su figura, ni que tampoco formara parte de la iconografía inicial recopilada por Jorge Eduardo Arellano. Mi investigación inconclusa respecto a la genealogía de este retrato, y a la sesión fotográfica que la produjo, me ha apuntado a otras dos imágenes relacionadas. Una imagen producida en la misma sesión fotográfica sí fue publicada el 10 de agosto de 1929 en México, en el periódico izquierdista llamado Clamor del Obrero bajo el titular "Gral. Augusto César Sandino”. ${ }^{23}$ Dicha imagen, tomada con el mismo telón de fondo y la misma vestimenta, excluye la mesita y el sombrero, presentándose Sandino con otra pose. Es curioso que la foto que circuló en su momento haya sido una que no incluyera el sombrero. Quizá la selección se deba a que en aquel momento el sombrero seguía teniendo connotaciones de la Revolución Mexicana y de Pancho Villa. Lo que sí queda claro es que esa imagen hoy se encuentra archivada, dada la importancia que el sombrero ha acogido en la iconografía posterior de resistencia nicaragüense. ${ }^{24}$ Es más, esa imagen no corresponde al imaginario contemporáneo de resistencia puesto que debajo del sombrero aparece un peinado exageradamente estilizado, que, pese a la bandolera que queda, elimina cualquier ambivalencia entre dandi y guerrillero, enfatizando el primero. Fuera de una revista de moda, hoy en día es evidente que en el imaginario visual de resistencia se suprima una representación tan andrógina.

El otro retrato que se produjo en esta sesión fotográfica es uno en el que aparece Sandino con seis representantes de su Estado Mayor, entre ellos Farabundo Martí. Los otros personajes incluidos en ese retrato colectivo son su medio hermano, Sócrates Sandino, el colombiano Rubén Ardilla Gómez, José de Paredes y el dominicano Gregorio Urbano Gilbert. Esta imagen presenta distintos grados de la masculinidad que Sandino anticipa. En un extremo se encuentra Sócrates Sandino con un traje de tres piezas y sombrero urbano y al otro lado Farabundo Martí con su bigote, sombrero y sin traje. La figura de Augusto C. Sandino no sólo se encuentra en el centro del retrato del grupo, sino que también sirve de intermediario visual entre los polos de esas masculinidades.

${ }^{23}$ El libro de Carlos Castilla Villanueva incluye entrevistas de personas que conocieron a Sandino durante su estadía en Yucatán y también documenta las publicaciones mexicanas a través de entrevistas y escritos sobre su lucha. En dicho libro aparece una copia de la primera página del Clamor Obrero que reproduce el otro retrato publicado y aquí mencionado (98).

${ }^{24}$ El título de esta imagen publicado en 1927 -“Gral. Augusto César Sandino”- enfatiza la puesta en escena y la teatralidad de la construcción del sujeto, puesto a que ése no era su nombre verdadero. Como sabemos, al nacer es nombrado Augusto Nicolás Calderón Sandino y su apellido materno (Calderón) será luego intercambiado por la letra "C", y luego por el nombre César, el cual supuestamente adopta para proteger su ilegitimidad al volverse imagen pública (Wünderich 37). El renombramiento se presenta como una maniobra de autoconstrucción del héroe como mito, evocando la tradición épica romana y alineándose a los protagonistas masculinos de la tradición occidental. Esta puesta en escena del nombre corresponde a la imagen fotográfica que aparece en la portada de Clamor del Obrero, y que ahora queda guardada en los archivos. El cambio del nombre apunta a la trayectoria revisionista de la historia y de la construcción de Augusto C. Sandino como mito nacional.

$\begin{array}{llllll}\text { Revista Iberoamericana, Vol. LXXIX, Núm. 242, } & \text { Enero-Marzo 2013, } & \text { 57-74 } \\ \text { ISSN 2154-4794 (Electrónico) }\end{array}$ 
ÚLTimo VISTAZO

Si como W. J. T. Mitchell sugiere, la vida de una imagen se mide según su capacidad de circular y modificarse de un medio a otro, entonces la vida de esta imagen de Sandino perdura (294). La imagen sigue vigente al ser una representación que codifica el legado de Sandino y de su lucha, insertándose en la iconografía nacional y regional de resistencia. Se trata de una imagen que reproduce los signos y referentes del México revolucionario: el Oeste estadounidense se encuentra con su homólogo del Sur, mientras también anticipa cierta imaginería de la Revolución Cubana.

En los últimos treinta años la imagen ha sido diseminada porque satisface el imaginario occidental contemporáneo de resistencia, arraigando múltiples referentes. Se puede decir que en el siglo xx todas las articulaciones de resistencia dependen de un collage icónico visual interdependiente. Es así que la imagen de Sandino ha figurado, además de en su contexto nacional, en la articulación de nuevas formas de resistencia. Pienso en particular en el movimiento zapatista y en la caracterización que hizo Guillermo Gómez Peña respecto a su líder: "His persona was a carefully crafted collage of twentieth-century revolutionary symbols, costumes, and props borrowed from Zapata, Sandino, Che, and Arafat as well as from celluloid heroes such as Zorro and Mexico's movie wrestler, 'el Santo'” (91). El legado de Sandino queda plasmado en una narrativa biogeográfica que encadena la Revolución Mexicana con la Revolución Cubana, ahora posiblemente también repercutiendo en el imaginario visual del movimiento zapatista.

Dado su contexto histórico, la ambivalencia entre guerrillero y dandi, entre vaquero y actor, es la manifestación específica de Sandino en su esmero por forjar una representación intertextual de su figura pública y de su forma de diseñar una narrativa visual transnacional de resistencia. Se trata de una representación teatralizada para representar un discurso que corresponde a la imagen puesta en escena. Es así que esta representación visual ha sido apropiada tanto por el proyecto sandinista como por los liberales, precisamente por mezclar signos políticos que en la práctica actual se han hecho indivisibles. Al igual que muchas de las representaciones de militantes, en esta imagen se acechan transformaciones históricas de dinámicas geopolíticas y sus respectivos códigos de transmisión. La identidad de Augusto C. Sandino es inseparable, y además ha sido sometida, como aquí vemos, a un proceso de iconificación, resultado en este caso de la autoconstrucción propia que llevó a cabo el hombre de acción. Este proceso sigue su curso con la apropiación histórica que se hizo posteriormente de su acción. De esta manera la fotografía ilustra la problemática misma que gira entorno no sólo a la figura de Sandino, sino también de sus propios escritos. A partir de la ambigüedad visual que aquí aparece vemos cómo este mismo desfase constituye la problemática crítica que Sandino, sus textos y su legado nos presentan.

$\begin{array}{llllll}\text { ISSN 2154-4794 (Electrónico) } & \text { Revista Iberoamericana, Vol. LXXIX, Núm. 242, }\end{array}$ 
BiBliografíA

Arellano, Jorge Eduardo, ed. Sandino: iconografía básica. Managua: Banco Central de Nicaragua, 1979.

“Augusto César Sandino”. Wikipedia. <http://en.wikipedia.org/wiki/ Augusto_C\%3\%A9sar_Sandino>. 1 dic. 2009.

Barthes, Roland. “The Photographic Message”. Image Music and Text. Stephan Heath, trad. Nueva York: Hill and Wang, 1999. 15-32.

Banco Central de Nicaragua. Nicaragua. Tove Blom, ed. Managua: Banco Central, 1997.

Baudelaire, Charles. The Painter of Modern Life and Other Essays. Jonathan Mayne, trad. Londres: Phaidon, 1964.

Benjamin, Walter. "Little History of Photography”. Tomo 2. Selected Writings: 19271934. Michael W. Jennings, Howard Eiland y Gary Smith, eds. Massachusetts: Belknapp, 1999. 506-30.

Bolaños Geyer, Alejandro. El iluminado. Masaya: sin editor, 2001. Sandino. Masaya: sin editor, 2002.

Castilla Villanueva, Carlos. Sandino en Yucatán, 1929-1930. México: Secretaría de Educación Pública, Programa Cultural de las Fronteras, 1988.

Fonseca Amador, Carlos. Ideario político de Augusto César Sandino. 6a. ed. Managua: Departamento de Propaganda y de Educación Política del F.S.L.N., 1984.

Sandino: guerrillero proletario. Managua: Departamento de Propaganda y de Educación Política del F.S.L.N., 1984.

Grandin, Greg. Empire's Workshop: Latin America, the United States and the Rise of the New Imperialism. Nueva York: Metropolitan, 2006.

Grossman, Richard. “Augusto Sandino of Nicaragua: The Hero Never Dies”. Heroes and Hero Cults in Latin America. Samuel Brunk y Ben Fallaw, eds. Austin: U of Texas P, 2006.

Gómez, Peña Guillermo. “The Subcomandante of Performance”. First World, Ha Ha Ha! The Zapatista Challenge. Elaine Katzenberger, ed. San Francisco: City Lights Books, 1995.

Hodges, Donald Clark. Sandino's Communism: Spiritual Politics for the Twenty-First Century. Austin: U of Texas P, 1992.

Kracauer, Siegfried. Theory of Film: The Redemption of Physical Reality. Miriam Bratu Hansen, ed. Princeton: Princeton UP, 1997.

Latuff, Carlos. “Ernesto Che Guevara”. Caricatura. 15 dic. 2002. Indymedia 15 dic. 2009.

López Bernal, Carlos Gregorio. “Alberto Masferrer y Augusto César Sandino: Espiritualismo y utopía en los años veinte”. Humanidades IV/2 (2003): 25-49.

Medina, Julia. "Desmitificación de un ícono: Augusto C. Sandino y sus manifiestos de urgencia”. América Latina: Giro óptico. Ignacio Sánchez Prado, ed. México: Universidad de las Américas, 2006.

Revista Iberoamericana, Vol. LXXIX, Núm. 242, Enero-Marzo 2013, $57-74$
ISSN 2154-4794 (Electrónico) 
Mitchell, W. J. T. What Do Pictures Want? The Lives and Loves of Images. Chicago: U of Chicago P, 2005.

Navarro-Génie, Marco A. Augusto "César" Sandino: Messiah of Light and Truth. Nueva York: Syracuse UP, 2002.

Rage Against the Machine. Bombtrack. Epic Label, 1993.

Revista Ariel. Tegucigalpa, 1926-1927.

Rodríguez, Ileana. Women, Guerrillas, and Love: Understanding War in Central America. Minneapolis: U of Minnesota P, 1996.

Rugg, Linda Haverty. Picturing Ourselves: Photography \& Autobiography. Chicago: U of Chicago P, 1997.

Saldaña-Portillo, María Josefina. The Revolutionary Imagination in the Americas and the Age of Development. Durham: Duke UP, 2003.

Said, Edward. Representations of the Intellectual: The 1993 Reith Lectures. Londres: Vintage, 1996.

Sandino, Augusto C. El pensamiento vivo. Sergio Ramírez, ed. 2 vols. Managua: Editorial Nueva Nicaragua, 1984.

Selser, Gregorio. Nicaragua: de Walker a Somoza. México: Mex Sur, 1984.

Sheesley, Joel. Sandino in the Streets. Wayne G. Bragg, trad. Bloomington: Indiana UP, 1991.

Schroeder, Michael J. "Bandits and Blanket Thieves, Communists and Terrorists: The Politics of Naming Sandinistas in Nicaragua, 1927-36 and 1979-90”. Third World Quarterly 26/1 (2005): 67-86.

Somoza García, Anastasio. El verdadero Sandino o el calvario de las Segovias. Managua: Tipografía Robelo, 1936.

Tamony, Peter. “The Ten-Gallon or Texas Hat”. Western Folklore 24 (1965): 115-18.

Torres, Edelberto. Sandino y sus pares. Nicaragua: Nueva Nicaragua, 1983.

Turok, Antonio. Imágenes de Nicaragua. México: Casa de las Imágenes, 1988.

Wünderich, Volker. Sandino: una biografía política. Managua: Nueva Nicaragua, 1995.

Zimmermann, Matilde. Sandinista: Carlos Fonseca and the Sandinista Revolution. Durham: Duke UP, 2000. 